\title{
Aarskog-Scott syndrome
}

INSERM

\section{Source}

INSERM. (1999). Orphanet: an online rare disease and orphan drug data base. Aarskog-

Scott syndrome. ORPHA:915

Aarskog-Scott syndrome (AAS) is a rare developmental disorder characterized by facial, limbs and genital features, and a disproportionate acromelic short stature. 